\title{
Erratum
}

\section{Sustainable Click Reaction Catalyzed by Supported Ionic Liquid Catalyst (Cu-SILC)}

Hisahiro Hagiwara, * Hirokazu Sasaki, Takashi Hoshi, Toshio Suzuki Synlett 2009, 643.

Since all reactions were carried out in the presence of 1.2 equiv of triethylamine, all footnotes and the reference 21 should be revised as follows:

Table 1. ${ }^{a}$ Reaction was carried out at r.t. in $50 \%$ aq EtOH with 0.05 equiv of $\mathrm{Cu}-\mathrm{SILC}$ and 1.2 equiv of triethylamine, in which the $\mathrm{CuBr} \cdot \mathrm{SMe}_{2}$ (Cu loading: $0.18 \mathrm{mmol} / \mathrm{g}$ ) was immobilized with the aid of [bmim] $\mathrm{NTf}_{2}$.

Table 2. ${ }^{a}$ Reaction was carried out at r.t. with 0.05 equiv of $\mathrm{Cu}$-SILC and 1.2 equiv of triethylamine, in which the $\mathrm{CuBr} \cdot \mathrm{SMe}_{2}(\mathrm{Cu}$ loading: $0.18 \mathrm{mmol} / \mathrm{g})$ was immobilized on NDEAP-silica with the aid of [bmim] $\mathrm{NTf}_{2}$.

Table 3. ${ }^{\text {a }}$ Reaction was carried out at r.t. in $50 \% \mathrm{EtOH}$ with 0.05 equiv of $\mathrm{Cu}-\mathrm{SILC}$ and 1.2 equiv of triethylamine, in which copper salts (Cu loading: $0.18 \mathrm{mmol} / \mathrm{g}$ ) were immobilized on mercaptopropyl $\mathrm{SiO}_{2}$ with the aid of $\left[\mathrm{bmim} \mathrm{PF}_{6}\right.$.

Table 4. ${ }^{\text {a }}$ Reaction was carried out at r.t. in $50 \% \mathrm{EtOH}$ with 0.05 equiv of $\mathrm{Cu}-\mathrm{SILC}$ and 1.2 equiv of triethylamine, in which the $\mathrm{CuBr} \cdot \mathrm{SMe}_{2}$ was immobilized on mercaptopropyl $\mathrm{SiO}_{2}$ with the aid of [bmim] $\mathrm{NTf}_{2}$.

Table 5. ${ }^{\text {a }}$ Reaction was carried out at r.t. in $50 \%$ aq EtOH with $0.07 \sim 0.08$ equiv of $\mathrm{Cu}$-SILC and 1.2 equiv of triethylamine, in which the $\mathrm{CuBr} \cdot \mathrm{SMe}_{2}$ was immobilized on mercaptopropyl $\mathrm{SiO}_{2}$ with the aid of [bmim] $\mathrm{PF}_{6}$.

Table 6. ${ }^{\text {a }}$ Reaction was carried out at r.t. in $50 \%$ aq EtOH with $0.05 \sim 0.08$ equiv of Cu-SILC and 1.2 equiv of triethylamine, which was prepared from $\mathrm{CuBr} \cdot \mathrm{SMe}_{2}$.

\section{Reference 21:}

Click Reaction of Benzylazide and 2-Methylbut-3-yn-2-ol: A suspension of benzylazide ( $65 \mathrm{mg}, 0.49 \mathrm{mmol})$, 2methylbut-3-yn-2-ol (51 mg, $0.61 \mathrm{mmol})$, triethylamine $(84 \mathrm{~mL}, 0.6 \mathrm{mmol})$ and Cu-SILC (299 $\mathrm{mg}, 0.035 \mathrm{mmol}$ of $\mathrm{CuBr})$ in $50 \%$ aq EtOH ( $2 \mathrm{~mL}$ ) was stirred at r.t. for $2 \mathrm{~h}$. The organic layer was separated by filtration and the flask was rinsed with $\mathrm{Et}_{2} \mathrm{O}$. Combined organic layer was evaporated to dryness in vacuo. The residue was purified by column chromatography (eluent: $n$-hexane-ethyl acetate $=3: 1$ to 1:5) to give 2-[1-benzyl-1,2,3-triazol-4-yl]propan-2-ol 3a (96 $\mathrm{mg}, 91 \%)$. Recovered $\mathrm{Cu}-\mathrm{SILC}$ was used intact for further recycle experiments. 